\title{
Study of demography and clinical profile of ectopic pregnancies in a tertiary level hospital in Uttarakhand: a five-year review
}

\author{
Shweta Nimonkar, Priyanka Chaudhari*, Namrata Saxena, Vineeta Gupta, \\ Archna Tandon, Parul Singh
}

\begin{abstract}
Department of Obstetrics and Gynecology, Shri Guru Ram Rai Institute of Medical and Health Sciences, Dehradun, Uttarakhand, India
\end{abstract}

Received: 14 March 2020

Accepted: 04 April 2020

\section{*Correspondence:}

Dr. Priyanka Chaudhari,

E-mail: dishitapriya07@gmail.com

Copyright: (c) the author(s), publisher and licensee Medip Academy. This is an open-access article distributed under the terms of the Creative Commons Attribution Non-Commercial License, which permits unrestricted non-commercial use, distribution, and reproduction in any medium, provided the original work is properly cited.

\begin{abstract}
Background: Ectopic pregnancy is a condition when a fertilized ovum is implanted outside the uterine cavity. Life threatening risk of rupture of ectopic pregnancy remains one of the important causes of maternal mortality in India. The aim of study is to analyse the clinical profile, associated risk factors, complications, treatment outcomes to improve maternal mortality and morbidity associated with ectopic pregnancy.

Methods: It is a retrospective study conducted at Shri Guru Ram Rai Institute of Medical and Health Sciences from January 2015 to January 2020. A total of 182 patients diagnosed of Ectopic Pregnancy were analysed for clinical profile, risk factors, serology, ultrasound findings, complications, treatment offered and outcome.

Results: During the study period of 5 years there were total 182 patients who were diagnosed of ectopic pregnancy showing the incidence of ectopic pregnancy in our hospital $1.4 \%$ of total number of deliveries. Majority of patients were in the age group of 25 to 30 years (43.95\%). Mostly multiparous women $(80.1 \%)$ had ectopic pregnancy. Majority of patients $(56.1 \%)$ had no associated risk factors for ectopic pregnancy. Main presenting complain was abdominal pain in $58.8 \%$ of patients. Majority of patients $(63.2 \%)$ had surgery as primary care which indicates delay in diagnosis and arrival at hospital especially in hilly region of Uttarakhand.

Conclusions: Ectopic pregnancies need to be diagnosed timely to decrease maternal morbidities and mortalities. Clinical signs and symptoms with serology (Serum beta hCG) and radiological findings helps to optimize treatment for potentially life-threatening condition.
\end{abstract}

Keywords: Ectopic pregnancy, Methotrexate, Salpingectomy, Serum beta hCG

\section{INTRODUCTION}

An ectopic pregnancy is defined as a pregnancy where implantation occurs in a site other than the uterine cavity. ${ }^{1}$ The most common site is fallopian tube other sites being ovary, cervix, peritoneal cavity, broad ligament , caesarean scar etc. ${ }^{2}$ The exact incidence is not known precisely but studies suggest an incidence of 0.25 $2.0 \%$ worldwide. ${ }^{3}$ Globally the incidence has been on rise over the past few decades because of increasing number of sexually transmitted diseases, pelvic inflammatory diseases, assisted reproductive techniques, tubal surgeries and better healthcare facilities leading to early detection of ectopic pregnancies. ${ }^{4}$ Though the cases of ectopic pregnancy are on rise, the incidence of rupture and maternal deaths have declined due to early diagnosis and management..$^{5}$ In spite of better healthcare facilities, ectopic pregnancy remains one of the important cause of maternal deaths in India accounting to $3.5-7.1 \%$ of maternal deaths. ${ }^{6}$ The study was aimed at understanding the incidence, clinical profile, presentation, associated risk factors, complications, serological and radiological correlation with clinical picture, treatment and their outcomes. 


\section{METHODS}

Our study is a retrospective study conducted at SGRRIM and HS, Dehradun which is a tertiary care referral centre of Uttarakhand. The detailed data of five years from January 2015 to December 2019 was analysed. All patients diagnosed with ectopic pregnancies based on clinical presentation serology and radiological findings during this duration were included in the study.

Data was collected and analyzed in terms of age, parity, risk factors, presenting complains, period of amenorrhea, complications, correlation of serum beta hCG levels and radiological findings with clinical picture, treatment offered and final outcome.

\section{Inclusion criteria}

- Patients diagnosed of ectopic pregnancy based on clinical features, positive urine pregnancy test and radiological findings suggestive of ectopic pregnancy were included in the study.

- All diagnosed patients of ectopic pregnancy managed by expectant, medical or surgical methods were included in the study.

\section{Exclusion criteria}

- Those patients who presented with positive urine pregnancy test but no evidence of any gestational sac on ultrasonography were followed by serial serum beta hCG levels and repeat ultrasound done after 7 to 10 days or earlier when clinically indicated.

- Those cases were excluded from the study in which repeat ultrasound and serum beta hCG suggested the diagnosis of abortion or intrauterine pregnancy.

\section{RESULTS}

During the study period of 5 years there were total 182 patients who were diagnosed of ectopic pregnancy. The incidence of ectopic pregnancy in study hospital was $1.4 \%$ of total number of deliveries. Majority of patients were in the age group of 25 to 30 years $(43.95 \%)$ followed by age group of 20-25 years (24.2\%) and $7.1 \%$ of patient were above the age of 35 years (Table 1). Table 2 shows that the incidence was highest in third gravidas $(31.3 \%)$ followed by second gravidas (24.7\%). Primigravidas were $18.7 \%$.

Table 1: Age wise distribution of ectopic pregnancy.

\begin{tabular}{|lll|}
\hline Age (years) & Number $(\mathbf{n}=\mathbf{1 8 2})$ & Percentage \\
\hline$<20$ & 3 & $1.6 \%$ \\
\hline $20-25$ & 44 & $24.2 \%$ \\
\hline$>25-30$ & 80 & $43.9 \%$ \\
\hline$>30-35$ & 42 & $23.1 \%$ \\
\hline$>35-40$ & 10 & $5.5 \%$ \\
\hline$>40$ & 03 & $1.6 \%$ \\
\hline
\end{tabular}

Table 2: Parity wise distribution.

\begin{tabular}{|lll|}
\hline Parity & Number $(\mathbf{n}=\mathbf{1 8 2})$ & Percentage \\
\hline G1 & 34 & $18.7 \%$ \\
\hline G2 & 45 & $24.7 \%$ \\
\hline G3 & 57 & $31.3 \%$ \\
\hline G4 & 27 & $14.8 \%$ \\
\hline$>$ G5 & 17 & $9.3 \%$ \\
\hline
\end{tabular}

Table 3: Risk factors.

\begin{tabular}{|lll|}
\hline Risk factors & Number $(\mathbf{n = 1 8 2})$ & Percentage \\
\hline $\begin{array}{l}\text { Previous ectopic } \\
\text { pregnancy }\end{array}$ & 16 & $8.8 \%$ \\
\hline H/O tubal ligation & 12 & $6.6 \%$ \\
\hline MTP pills & 24 & $13.2 \%$ \\
\hline H/O tuberculosis & 4 & $2.2 \%$ \\
\hline H/o tubal surgery & 12 & $6.6 \%$ \\
\hline Infertility & 12 & $6.6 \%$ \\
\hline Unexplained & 102 & $56.1 \%$ \\
\hline
\end{tabular}

Many associated risk factors were identified, $8.8 \%$ patients had previous history of ectopic pregnancies, $6.6 \%$ patients had history of tubal ligation and $13.2 \%$ patients gave history of unsupervised medical abortion pills intake (Table 3 ).

Table 4: Presenting symptoms.

\begin{tabular}{|lll|}
\hline Symptoms & Number $(\mathbf{n}=\mathbf{1 8 2})$ & Percentage \\
\hline Abdominal pain & 107 & $58.8 \%$ \\
\hline Bleeding p/v & 32 & $17.6 \%$ \\
\hline $\begin{array}{l}\text { Both (pain and } \\
\text { bleeding) }\end{array}$ & 31 & $17 \%$ \\
\hline Asymptomatic & 12 & $6.6 \%$ \\
\hline Fainting & 10 & $5.5 \%$ \\
\hline Shock & 8 & $4.4 \%$ \\
\hline
\end{tabular}

According to the clinical profile, $58.8 \%$ patients presented with abdominal pain while $17.6 \%$ patients came with unscheduled bleeding per vaginum as presenting complain, $17 \%$ patient had both symptoms of pain associated with unscheduled vaginal bleeding. Among all, 6.6\% patients were asymptomatic and only had amenorrhea.

There was history of fainting episode in $5.5 \%$ patients and $4.4 \%$ patients came to emergency in hypovolemic shock (Table 4).

Table 5: Haemoglobin levels on admission.

\begin{tabular}{|lll|}
\hline Haemoglobin (gm \%) & $\begin{array}{l}\text { Number } \\
(\mathbf{n = 1 8 2})\end{array}$ & Percentage \\
\hline$>=10$ & 86 & $47.3 \%$ \\
\hline $7-<10$ & 67 & $36.8 \%$ \\
\hline $5-<7$ & 23 & $12.6 \%$ \\
\hline$<5$ & 06 & $3.3 \%$ \\
\hline
\end{tabular}


According to the amount of blood loss at the time of first presentation, $47.3 \%$ patients had haemoglobin of 10 $\mathrm{gm} / \mathrm{dl}$ or more, $3.3 \%$ patients had haemoglobin less than $5 \mathrm{gm} / \mathrm{dl}, 12.6 \%$ patients had haemoglobin less than 7 $\mathrm{gm} / \mathrm{dl}$ (Table 5).

Treatment was decided primarily on clinical profile of the patient and was supported by serological and radiological findings. A total of $36.8 \%$ patients were managed by conservative approach by offering expectant or medical management and $63.2 \%$ patients were managed surgically. Surgery was done in emergency as primary modality of care in all hemodynamically unstable patients or who had failed medical management. Surgery was also done in some patients who refused for medical management. In this study among 26 patients who underwent medical management, 5 of them had emergency surgery because of failed medical management (Table 6).

Table 6: Treatment.

\begin{tabular}{|lll|}
\hline Treatment & Number $(\mathbf{n = 1 8 2})$ & Percentage \\
\hline Expectant & 41 & $22.5 \%$ \\
\hline Medical management & 26 & $14.3 \%$ \\
\hline Surgical management & 115 & $63.2 \%$ \\
\hline Laparoscopic & 48 & $41.7 \%$ \\
\hline Laparotomy & 67 & $58.3 \%$ \\
\hline
\end{tabular}

\section{DISCUSSION}

There is a global rise in number of ectopic pregnancies which is due to better diagnostic modalities and early detection, increasing number of STD and PID patients, more infertile patients opting for fertility enhancing surgeries and assisted reproductive techniques etc. The incidence in this study was 14 per 1000 deliveries.

Majority of patient were in age group of 25 to 30 years accounting for $43.9 \%$ of total patients. A total of $68 \%$ patient were between 20-30 years in this study which was close to study done by Sudha VS et al who reported it to be $67.54 \% .^{7}$ This is the age group which is exposed to peak sexual activity in their reproductive age. But extreme age groups like less than 20 year and age more than 40 years also had $1.6 \%$ patients who had ectopic pregnancy emphasizing that no age group is barred. For majority of patients $(31.3 \%)$ it was their third conception which resulted in ectopic pregnancy. Primigravida were $18.7 \%$.

There were $81.3 \%$ multigravidas in this study which correlates with studies done by Sudha VS et al $81.58 \%$, Shetty $\mathrm{K}$ et al $(83.9 \%)$, Panchal $\mathrm{D}$ et al $81.66 \% .^{7-9}$ Exposure to previous D and Cs and abdominal surgeries like caesarean section may have a role to play as $24.2 \%$ patients had previous one or two caesarean sections. Among all, 29.7\% patients had previous abortions out of them $33.3 \%$ had history of dilatation and evacuation.
Total $16(8.8 \%)$ patients had previous history of ectopic pregnancy out of them 4 had two ectopic pregnancies. Nine out of 16 patients were managed surgically, all of them underwent salpingectomy. Remaining 7 were managed by medical or expectant method. Shubha VS et al had reported $8.33 \%$ and Mulfti S et al reported 5.26\% percent of patient in their respective studies with previous ectopic pregnancy. ${ }^{10}$

Twelve $(6.6 \%)$ patients had history of previous tubal sterilization. Shreshta et al has reported 5\% and Sudha Vs et al has reported $6.57 \%$ of previous tubal sterilization in their respective studies which was similar to this study. ${ }^{11}$ Improper surgical techniques, peripartum tubal congestion, formation of tubo-peritoneal fistula increases the chances of ectopic implantation.

A total of $6.6 \%$ patients had history of infertility treatments out of which two were the result of IVF conception. Twelve $(6.6 \%)$ patients had various tubal surgeries, 9 out of them had salpingostomy or tubal surgeries for ectopic pregnancy, for others exact details could not be retrieved. This again puts the study attention towards association of infertility and ectopic pregnancies. But since these patients are already under close monitoring of their fertility specialist, ectopic pregnancies get early recognized in these patients compared to others hence increasing the chances of conservative treatment in such patients.

Another important association was noted with unsupervised medical abortion seekers and ectopic pregnancies in this study. Twenty-four (13.2\%) patient had history of over the counter consumption of medical abortion pills. Seventeen out of 24 required immediate surgical management. Four patients out of those 24 patients came in hypovolemic shock with one patient had hemoglobin of $2.4 \mathrm{gm} / \mathrm{dl}$. Government needs to act stringently to limit unsupervised access of these medical abortion pills over the counter to reduce such severe morbidities.

Preceding amenorrhea of varying length was common in all the patients. A total of $58.8 \%$ patients had abdominal pain as presenting symptom while $17.6 \%$ patient reported unscheduled scanty bleeding per vaginum. Seventeen percent $(17 \%)$ patients presented with both abdominal pain as well as irregular bleeding per vaginum. Fainting episodes were described in $10(5.5 \%)$ patients and 8 $(4.4 \%)$ patients were brought in hypovolemic shock. There were no mortalities due to ectopic pregnancy in this study. For clinicians its prudent to keep in mind all these signs and symptoms for early diagnosis of ectopic pregnancies.

Six $(3.3 \%)$ patients had very severe anaemia with hemoglobin of less than $5 \mathrm{gm} / \mathrm{dl}, 23(12.6 \%)$ had severe anaemia with $\mathrm{Hb} \%$ between $5 \mathrm{gm} / \mathrm{dl}$ to $7 \mathrm{gm} / \mathrm{dl}$. Hemodynamic stability, hemoglobin level, serum beta hCG levels were crucial to determine the line of 
treatment whether medical/expectant or surgical to all patients.

Total $41(22.5 \%)$ patients who were hemodynamically stable, had S. beta hCG levels less than $1000 \mathrm{miu} / \mathrm{ml}$ were kept under expectant managements. By serial $\mathrm{S}$. beta hCG levels these patients were monitored and were discharged after observing satisfactory decline in levels of S. beta hCG.

Total $26(14.3 \%)$ patients were given medical management. Out of these 16 patients required single dose Methotrexate therapy while 10 were successfully managed by multi dose methotrexate therapy. 5 patients who were given medical management required surgical management.

Total $115(63.2 \%)$ patients underwent surgical procedure for their management. A total of 67 patient underwent laparotomies while 48 patients underwent laparoscopic surgeries. In study institute Laparoscopic procedures are done only in routine hours which limits the number of cases which can be managed laparoscopically. 28 patients who were undergoing surgery also consented for tubal sterilization of other tube concomitantly. Morbidity included anemia, shock, requirement of blood or blood products or ICU stay.

\section{CONCLUSION}

Ectopic pregnancy still remains one of the challenging conditions in obstetrics and gynaecology practice. Though increasing awareness, accessibility to healthcare facilities and better diagnostic modalities have definitely improved the outcome in these patients.

After careful selection conservative management may also be offered to those infertile patients who want tubal conservation in spite of not fitting in criteria defined by medical guidelines. This study puts focus on importance of understanding clinical signs, laboratory and imaging correlations to outline quick but comprehensive treatment in managing ectopic pregnancies.

Funding: No funding sources Conflict of interest: None declared

Ethical approval: The study was approved by the Institutional Ethics Committee

\section{REFERENCES}

1. Walker JJ. Ectopic pregnancy. Clin Obstet Gynecol. 2007;50:89-99.

2. Bouyer J, Coste J, Fernandez H, Pouly JL, Job-Spira N. Sites of ectopic pregnancy: a 10-year populationbased study of 1800 cases. Hum Reprod. 2002;17:3224-30.

3. Yadav A, Prakash A, Sharma C, Pegu B, Saha MK. Trends of ectopic pregnancies in Andaman and Nicobar Islands. Int J Reprod Contracept Obstet Gynecol. 2017;6(1):15-9.

4. Cummingham FG, Leveno, Bloon St, Hauth JC, Rouse DJ, Spong CY. Ectopic pregnancy; In Williams obstetrics, 23 United states of America MC Graw Hills Publishing; 2010:238-254.

5. Creanga AA, Shapiro-Mendoza CK, Bish CL, Zane $\mathrm{S}$, Berg CJ, Callaghan WM. Trends in ectopic pregnancy mortality in the United States: 19802007. Obstet Gynecol. 2011;117(4):837-43.

6. Tahmina S, Daniel M, Solomon P. Clinical analysis of ectopic pregnancies in a tertiary care centre in Southern India: a six-year retrospective study. J Clin Diagn Res. 2016;10(10):QC13-QC16.

7. Sudha VS, Delphine RT. A retrospective study on ectopic pregnancy: a two-year study. Int J Reprod Contracept Obstet Gynecol 2016;5:4365.

8. Shetty S, Shetty A. A clinical study of Ectopic pregnancies in a Tertiary care Hospital of Mangalore, India. Innovat J Med Health Sci. 2014;4(1):305-9.

9. Panchal D, Vasihanav G, Solanki K. Study of management in patients of ectopic pregnancy. Nat $\mathbf{J}$ Integr Res Med. 2011;2(3):91-4.

10. Shagufta SM, Samina M, Reyaz AR, Wasiqa K. Ectopic pregnancy; an analysis of 114 cases. JKPract. 2012;17(4):20-3.

11. Shrestha J, Saha R. Comparison of laparoscopyand laparotomy in the surgical management of ectopic pregnancy. J College Phys Surg Pak. 2012;20(12):760-4.

Cite this article as: Nimonkar S, Chaudhari $P$, Saxena N, Gupta V, Tandon A, Singh P. Study of demography and clinical profile of ectopic pregnancies in a tertiary level hospital in Uttarakhand: a five-year review. Int J Reprod Contracept Obstet Gynecol 2020;9:2127-30. 